\title{
Ideas sobre la nación entre trabajadores del petróleo
}

ESTEBAN VERNIK JORGELINA LOZA

Resumen: Aunque los estudios sobre la nación de finales del siglo XX se concentraron en afirmar su artificialidad, autorescomo Benedict Anderson mostraron que la nación era una construcción histórica, internamente heterogénea, que generaba profundos apegos en los sujetos. Partimos de ese enfoque para explorar ideas sobre la nación en un conjunto de trabajadores de la Patagonia argentina. Presentaremos nuestro marco teórico, luego la estrategia metodológica implementada $y$, finalmente, resultados preliminares.

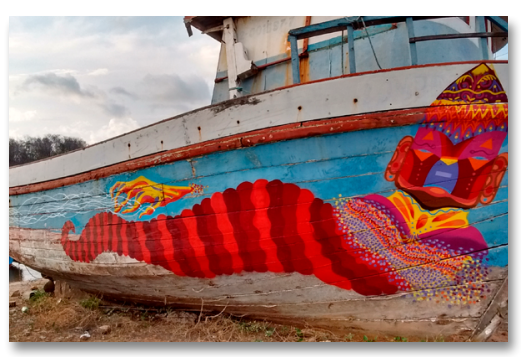

Palabras-clave:

Nación. Globalización. Anderson. Petróleo. Patagonia.

\section{Ideas about the nation among oil workers}

\section{Esteban VerniK}

Profesor de la Universidad de Buenos Aires y de la Universidad Nacional de la Patagonia Austral. Investigador del Consejo Nacional de Investigaciones Científicas y Técnicas y del Instituto de Investigaciones Gino Germani. Email: estebanjvernik@gmail.com

\section{JoRgELINA LozA}

Profesora de la Universidad de Buenos Aires. Investigadora del Consejo Nacional de Investigaciones Científicas y Técnicas y del Instituto de Investigaciones Gino Germani. Email: jorgelinaloza@yahoo.com.ar
Abstract: Although studies on the nation of the late twentieth century concentrated on affirming its artificiality, authors like Benedict Anderson showed that the nation was a historical construction, internally heterogeneous, that generated deep attachments in the subjects. We start from that approach to explore ideas about the nation in a group of workers from the Argentine Patagonia. We will present our theoretical framework, then the methodological strategy implemented and, finally, preliminary results.

Keywords: Nation. Globalization. Anderson. Petroleum. Patagonia.

$$
\begin{aligned}
& \text { RECEBIDO: } 15 / 02 / 2018 \\
& \text { APROVADO: } 02 / 05 / 2018
\end{aligned}
$$




\section{INTRODUCCIÓN}

Podemos pensar la nación como una configuración cultural que se basa en determinados elementos simbólicos, prácticas y espacios que tienden a su construcción, difusión y reproducción en el tiempo. Se trata de un entramado que incluye relatos de los procesos históricos, una variedad de significados y los elementos culturales que las luchas por la hegemonía vayan incorporando a la identificación.

Los estudios sobre la nación de finales del siglo XX se concentraron en afirmar la artificialidad de la misma en tanto construcción cultural. Aun cuando estas afirmaciones parecían poner en duda la relevancia de la pertenencia nacional para los sujetos, autores como Benedict Anderson se ocuparon de mostrar que la nación era una fuente de fuertes apegos para los sujetos. Es decir, aun cuando era la nación una construcción histórica, contingente y cargada de heterogeneidad, generaba apegos tan profundos como para que los sujetos entregaran su vida por esa idea. Esta afirmación acompañaba la descripción de la nación como construcción cultural y, entonces, como ficción compartida. Una ficción sostenida en el tiempo, diseminada por actores centrales a través de canales específicos y reproducida e imaginada por sujetos que nunca llegarían a conocerse entre sí. Se construía una comunidad simbólica que daba sustento a acciones políticas.

Sin embargo, el énfasis en lo ficcional de la idea de nación que sostuvieron algunos autores del siglo XX restó importancia a la reflexión sobre las bases materiales de las naciones y su influencia en esa construcción simbólica. Renan se preguntaba en 1881 por la relevancia del territorio para una nación y, desde el contexto en el que escribe su discurso, afirmaba que es una doctrina arbitraria y funesta la que establece la dominación de una nación sobre un territorio y la demarcación de sus fronteras. Aunque la tierra no le parece factor suficiente para "hacer" a una nación, admite que es la tierra lo que da sustento al principio espiritual que es una nación: "La tierra da el substratum, el campo de lucha y de trabajo" (RENAN, 2001 ,p.64). Es en el territorio donde la nación se disputa y se construye. En el proceso histórico de construcción de cada nación, la demarcación del territorio se fue definiendo en vinculación con 
otras naciones y en relación a la asimilación de los diversos pueblos que lo habitaban. Los recursos naturales de la nación ocuparon diferentes posiciones en la construcción de la idea de unidad nacional, otorgando el sustento que Renan (2001) menciona y a la vez construyendo la base material de la idea de nación.

Entre estas coordenadas - idea y sustrato - de lo nacional, el presente artículo parte principalmente del enfoque teórico de Benedict Anderson (1993) sobre las naciones como comunidades imaginadas, para interrogar acerca de las ideas sobre la nación que circulan en el imaginario de un conjunto de trabajadores del petróleo de la Cuenca del Golfo de San Jorge, en la provincia de Santa Cruz de Argentina. La referencia principal de las narrativas capturadas girará en torno a los contextos de la privatización (entre 1992 y 1999, durante los gobiernos de Carlos Menem) y la (re)nacionalización (2012, durante el último gobierno de Cristina Fernández de Kirchner) de la empresa estatal de petróleo. Nos preguntamos si, en la reflexión que estos trabajadores realizan sobre el proceso histórico de la empresa Yacimientos Petrolíferos Fiscales (en adelante, YPF), se encuentran también elementos capaces de dar cuenta de representaciones sobre el territorio, la nación, el Estado y la soberanía.

En la próxima sección presentaremos una breve descripción del marco teórico sobre imaginarios de la nación utilizado, centrándonos en las ideas del autor mencionado. A continuación, exploraremos algunos hallazgos en el análisis de la información recolectada por medio de un dispositivo de recolección de información en base a experiencias audiovisuales. Sobre éste y otros elementos heurísticos puestos en juego para la captación de representaciones sobre la nación, nos explayaremos en la sección siguiente, en la que también explicitaremos las dimensiones de las representaciones sobre la nación consideradas.

\section{IMAGI-NACIONES. SOBRE LAS COMUNIDADES IMAGINADAS}

Durante el siglo XX, las naciones comenzarán a ser cuestionadas en tanto artefactos. Su carácter ficcional es destacado, en principio, por pensadores constructivistas, que se proponen 
desandar el camino de grandes entramados simbólicos y arraigados relatos históricos sobre la nación. De acuerdo con esa línea de pensamiento, la Nación no existe desde siempre, sino que es una realidad histórica contingente que aparece en escena de manera estable en el siglo XVIII. El nacionalismo resulta aquí prioritario con respecto a la Nación - entendida como colectividad estable y como realidad histórica objetiva - dado que es el nacionalismo el que crea a la Nación. Como exponentes de esta corriente, pueden mencionarse junto a Benedict Anderson, a Ernest Gellner y Eric Hobsbawm, quienes intentan rastrear los elementos que permitieron el nacimiento del nacionalismo y la consiguiente invención de una tradición e identidad nacionales.

El reconocido trabajo de Benedict Anderson (1993) establecerá a la nación como una comunidad política imaginada: los sujetos imaginan al resto de los integrantes como condición para formar parte de ella, constituyendo una comunidad que entienden como horizontal. Para aceptar la existencia de pluralismo al interior de la misma y permitir la convivencia, la nación se imagina soberana. Es inherentemente limitada, además de soberana. Pero la nación nunca se imagina sola, sino rodeada de otras naciones. Anderson entiende a las naciones modernas como un fenómeno global: "(A mediados del siglo XX) Gradualmente se volvió claro que era imposible pensar el nacionalismo excepto de manera comparativa y globalmente" (ANDERSON, 1996, p.2, traducción nuestra). Las comunidades nacionales creadas desde el siglo XVII se volvieron modulares, es decir plausibles de ser trasladados a una variedad de terrenos sociales.

Los contenidos simbólicos de la nación son difundidos desde el aparato estatal hacia sus integrantes, favorecidos por el surgimiento de la imprenta y los medios de comunicación modernos. Esta es la dimensión en la que Anderson (1993) hará foco en su ya clásico libro y en sus análisis de procesos de construcción nacional (especialmente en Asia). Reconoce que parte de afirmar que la nacionalidad que se difunde es una clase particular de artefacto cultural.

La nación se imagina a sí misma como una comunidad, en la que un compañerismo profundo prima por sobre las desigualdades 
y la explotación entre sectores sociales. Si bien estas ideas confirman la condición ficcional de las naciones, no dejan ver el carácter conflictivo de su constitución, proceso en el que amplios grupos de sujetos quedan excluidos.

Al iniciar su crítica al trabajo de Anderson, Renato Rosaldo (1992) se pregunta si la categoría de nación en sí misma no se ha vuelto obsoleta en un mundo que visiblemente expone las diferencias entre incluidos y excluidos. La duda que recorre su digresión es acerca del modo en que puede resolverse la discusión intelectual sobre al concepto de nación de forma tal que resuenen en su interior identidades desiguales y en permanente conflicto. Afirma que es necesario tener en cuenta que las comunidades de filiación identitaria y las naciones como tales están en permanente reconsideración y sus límites no están definitivamente resueltos. Las cuestiones relativas a las identidades nacionales aparecen como ficcionales, pero al mismo tiempo como ámbitos de negociación, lucha por el poder simbólico y conflicto. Sin embargo, tener en cuenta este carácter ficcional no implica, de ningún modo, desestimar la fuerza de la nación como artefacto cultural. Destaca Rosaldo, entonces, siguiendo la línea de Norbert Elias, que las construcciones nacionales refieren a procesos históricos que no pueden analizarse separados de los contextos en que han nacido y se han desarrollado (ROSALDO, 1992).

La pregunta que subyace a estas críticas a un texto ya clásico de la teoría sobre la nación, es sobre la posibilidad de ser ciudadano de una nación, aun siendo diferente al todo que la nación promueve y reproduce. Esta pregunta refiere más profundamente a los márgenes de acción de los sujetos frente a nacionalismos que son construidos en procesos históricos de los que no parecen haber formado parte. Los sujetos que se identifican como excluidos construyen estrategias de (re)definición de sus filiaciones a un todo nacional, estrategias que se hallan en constante negociación con las ficciones "oficiales", por así decirlo. Concluye Rosaldo: "La filiación a las comunidades nacionales imaginadas parece ser un contrato que requiere constante renegociación. Vale la pena preguntar quién fue invitado a la fiesta y quién no" (ROSALDO, 1992, p.201). 
Anderson no deja de lado estas cuestiones, sino que parece enfocarse en otro aspecto: el proceso de construcción de un artefacto cultural que aglutina personas que conviven en un mismo territorio. "La magia del nacionalismo es la conversión del azar en destino" (ANDERSON, 1993, p.29), dirá al referirse a la construcción de la nación como un artefacto que explica la existencia de esa comunidad. Ese destino aparece fuertemente marcado en quienes se muestran dispuestos a grandes sacrificios, incluso a dejar la vida por la patria (la nación en su forma más emocional). Gopal Balakrishnan sostuvo, respecto de las reflexiones que Anderson hace en este punto, que la nación en tanto comunidad imaginada, tiene tanta fuerza en cuanto es la combinación de elementos seculares y sagrados. En su crítica a las lecturas de los procesos de construcción nacional por parte de muchas posiciones del marxismo, Anderson subraya que el hecho de que existan personas dispuestas a dar la vida por la nación, demuestra que el orden social moderno también suele evocar imaginaciones sagradas poderosas como sentido último de las acciones humanas. Lo sagrado y lo secular parecen órdenes antagónicos, pero - para Anderson - se entrecruzan en los artefactos del Estado-nación (BALAKRISHNAN, 1996).

Las preguntas por el sustento de las grandes ideas nacionales, aun revelada su ficcionalidad, adquiere mayor fuerza frente a los conflictos raciales y étnicos contemporáneos. Son los pensadores poscolonialistas, especialmente aquellos que tratan con contextos de alta violencia, quienes lanzan la pregunta por los actores intervinientes en la construcción de esas ideas, y la posibilidad de la existencia de representaciones contrapuestas frente a símbolos que se evidencian ambiguos y excluyentes. En ese sentido, Partha Chatterjee relatará los procesos de conformación de los Estados-nación modernos, como situaciones en las que diferentes discursos compiten entre sí, hasta que se impone un discurso elitista que logra dominar una alianza nacional que asumirá como tarea histórica el proceso de consolidación nacional, excluyendo a sectores subalternos que competían por esa posición dominante. Así, afirma la posibilidad de que existan nacionalismos anticoloniales capaces de construir "espacios de soberanía" en el campo 
espiritual, por fuera de la batalla política (CHATTERJEE, 2008, p.93). Este argumento le permitió al historiador indio desarrollar una extensa crítica a la teoría andersoniana sobre la nación, subrayando aque que Rosaldo mencionaba: la ausencia de diversidad ( $\mathrm{y}$, entonces, conflicto) en las imaginaciones sobre la comunidad nacional. Anderson resaltará que esa crítica permitió poner en el centro del debate el origen imperial de los procesos de construcción nacional en las ex colonias de América, Asia y África, dando a entender que esos procesos de subalternización o dominación son propios de las naciones no europeas (ANDERSON, 1996).

Además de la relevancia del capitalismo impreso - en especial el rol de periódico y la novela como vehículos difusores de estilos de vida -, Anderson destaca el accionar de un conjunto de herramientas estatales que permitieron consolidar esas ideas. La expansión de la administración estatal hacia la comunidad a través del censo, el mapa, los monumentos y los museos, fueron clave para el fortalecimiento y materialidad de esas imaginaciones. El mapa permitió incorporar a la comunidad imaginada la figura del territorio en tanto símbolo: un territorio que nunca se conocerá en su totalidad pero cuya extensión legitima el accionar del Estado. El mapa constituye una narrativa política, que contiene la historia de la comunidad. De esta forma, el mapa institucionaliza la forma en que se imaginan los límites, los vínculos entre los actores, los recursos de una comunidad nacional. En este punto, Calhoun (2016) sostiene que lo que Anderson hace explícito es que esa imaginación sirvió para formar y solidificar a la comunidad nacional, y que el énfasis en la importancia del capitalismo impreso le permitió afirmar que tal formación nacional simbólica tiene, a su vez, fundamentos materiales concretos.

A estas bibliografías sobre la nación, hasta aquí brevemente reseñadas, habremos de complementarlas con una reflexión sobre la avanzada que el desarrollo del capitalismo mundial produce actualmente sobre el conjunto de las identificaciones que realizan los sujetos. Esta homogenización que pugna por desrealizar las identidades tradicionales, incluye también las identidades nacionales, con las que se mantendrá en conflicto. Encontramos elementos teóricos sustantivos para esta reflexión en la obra 
dejada por el filósofo ecuatoriano Bolívar Echevería, quien a partir del concepto de blanquitud, elaboró una interpretación del proceso de modernización universal capitalista que muestra un progresivo borramiento de las identidades culturales de los sujetos en aras de una enajenante identificación pura con los componentes utilitarios de su inserción en los procesos productivos. Para este autor, la blanquitud refiere a la instalación de un orden ético universalizante, que toma como referencia central a la cultura europea. El eurocentrismo se revela no como un lugar en el mundo, sino como una referencia cultural totalizante. El racismo que el capitalismo instala, entonces, refiere a la anulación de identidades diversas que son oprimidas y reprimidas en el proceso hacia la construcción de un "grado cero" de la identidad moderna. El grado cero identitario representa el ideal humano de funcionalidad técnica y moral en relación con la reproducción de la riqueza, en el proceso universal de acumulación del capital. Es decir, que los individuos alcanzan la modernidad en tanto se aproximan a este grado cero, en tanto incorporan el ethos capitalista (ECHEVERRÍA, 2007).

Así, la actual fase de globalización del capitalismo contemporáneo, parece orientar a los sujetos hacia un "grado cero" de la identidad cultural, reduciendo sus imaginarios a una férrea ética utilitarista de la producción. ${ }^{1}$ El capitalismo se sostendría, entonces, en una constante interacción entre el proceso universalizante de integración (asimétrica) a un mismo proceso histórico, y las construcciones particulares como las naciones. Buscaremos en las narraciones recuperadas, elementos que refieran a esa identificación utilitaria con el proceso de acumulación capitalista y su tensión con la permanencia - siempre en construcción y en estado transitorio - de la identidad nacional argentina. No obstante, antes de confrontarnos con el material de tales testimonios, debemos referirnos en lo que sigue a aspectos metodológicos de nuestra recolección de información en base a experiencias audiovisuales.

\footnotetext{
1 Puede percibirse aquí la inspiración que Bolívar Echeverría toma de los sociólogos de la Modernidad de inicios del siglo XX, en particular de Max Weber, quien vislumbraba un futuro en el que el proceso de secularización se orientaría a la pérdida de las identidades, concibiendo las tradiciones identitarias como el peor enemigo del capitalismo.
} 


\section{ESTRATEGIA DE APROXIMACIÓN}

Si focalizamos en los diversos discursos sobre la idea de nación que trasmite la televisión, el medio mayor de comunicación de masas, aquel que en simultaneidad conecta a las mayorías nacionales, habremos de necesariamente confrontarnos con la esfera de reconocimiento de tales discursos político-televisivos sobre la nación.

Este artículo presenta los avances de una investigación que analiza representaciones de la idea de nación a partir del material producido en un conjunto de experiencias audiovisuales de las que participaron trabajadores petroleros residentes en la Patagonia argentina, que - a lo largo de distintos momentos de sus ciclos laborales - fueron empleados de YPF. ${ }^{2}$ En esas experiencias, desarrolladas entre 2015 y 2016, se buscó obtener información sobre la recepción que diferentes sujetos sociales realizan sobre fragmentos del discurso televisivo referido a la idea de nación. Las dimensiones que se tuvieron en cuenta para la segmentación macro y micro fueron la vinculación con las prácticas laborales de los sujetos en general, y con el trabajo de transmisión de la idea nacional en particular; el nivel socioeconómico y el nivel sociocultural.

La decisión de segmentar la muestra de acuerdo a estas dimensiones obedeció tanto a la temática de la investigación - esto es, la "idea de nación" entre diferentes sujetos sociales -, como a la intención de analizar una diversidad en cuanto a la distribución del capital económico y escolar de los participantes.

En cuanto a la utilización de un dispositivo de captación de información como forma de aproximarse empíricamente a los sujetos, tal opción se apoya en una serie de antecedentes de investigación que parten de un uso del modelo de "Codificación/decodificación" propuesto por Stuart Hall (1993). Este supone la realización de series de observaciones cualitativas en pequeños universos, con el objetivo de explorar los modos en que los discursos son

\footnotetext{
2 "La idea de nación en las narrativas del petróleo. Representaciones de la nación y la globalización entre trabajadores petroleros de la Cuenca del Golfode San Jorge" (Director E. Vernik), Instituto de cultura, identidad y comunicación, Universidad Nacional de la Patagonia Austral, Unidad Académica Caleta Olivia, proyecto en curso. Agradecemos la colaboración de nuestros compañeros Aylem Righi Luperti y Milton Riquelme.
} 
decodificados por la comunidad de apropiación. Estos diversos de modos de apropiación son considerados según las categorías propuestas en el modelo, de aceptación dominante, negociada, y en oposición. Siguiendo el modelo de Hall, distintas investigaciones han optado por la aplicación de distintas técnicas cualitativas, tales como grupos focales y entrevistas en profundidad (ANG, 1985; MORLEY, 1980; VERNIK, 1996). Todos estos casos tienen en común con la presente investigación que se realizan sobre muestras de pequeño tamaño y que no pretenden generalizar sus resultados a un universo más amplio. Esto último no significa proponer, sin embargo, que el análisis no deba situarse también en un marco mayor de relaciones estructurales.

En este caso, el modelo de Hall se complementó a su vez con el aporte de la bibliografía que aborda la problemática de las etnografías (MARCUS; FISCHER, 1986; CLIFFORD; MARCUS, 1986), lo que permite introducir en esta investigación la cuestión de la "etnografía de audiencias" o "etnografía de la lectura", proclives a comprender las diferentes formas de relacionamiento de las personas con la televisión y/u otros medios (ANG, 1985). En nuestro caso, se asume que el grupo focal es, como entrevista grupal centrada en la interacción, un canal efectivo para captar la actividad hermenéutica de los receptores. La elección de la técnica de grupo focal tuvo que ver con la intención de favorecer una de las improntas centrales de esta técnica: la interacción grupal como ámbito de intercambio y formación de opiniones. En efecto, la dinámica grupal permite al moderador impulsar la interacción complementaria (consenso) y argumentativa (disenso) (PETRACCI, 2004), lo que enriquece la discusión intragrupal sin la necesidad de buscar consensos entre las opiniones de los participantes. Sin embargo, de acuerdo a los objetivos de la investigación, se operaron modificaciones en las modalidades clásicas de aplicación del grupo focal. Por un lado, y como ya fue indicado, siguiendo los usos del modelo de Hall se aplicó un estímulo audiovisual ${ }^{3}$ con el objetivo de poner en acción los mecanismos de decodificación

3 Se incluye en anexo un guión descriptivo y analítico sobre los contenidos del dispositivo audiovisual utilizado. 
de los grupos; por otro, en razón del énfasis asumido por esta investigación en la etnografía de audiencias, se decidió trabajar con sujetos que fueran parte de una comunidad preexistente, y no con sujetos que se encontraban por primera vez en esa ocasión (tal como indicaría una aplicación estricta de esta técnica). Como lo señala la bibliografía sobre el tema, la noción de "comunidad interpretativa" es útil para referirse a conjuntos de personas que comparten similares condiciones socioeconómicas y - lo que es más importante - tradiciones culturales, significados y convenciones. Siguiendo a Klaus Brhun Jensen (1987), se ha entendido a los grupos participantes en las experiencias como comunidades de apropiación, esto es, conjuntos de personas con lazos preexistentes, que comparten tradiciones culturales y una serie más o menos estabilizada de significados acerca de lo social, y también niveles homogéneos de acceso a los bienes materiales. Esto significa entender a las comunidades de apropiación tanto en el sentido de "comunidades imaginadas" (ANDERSON, 1993), como en el sentido de comunidades propiamente materiales, esto es, conjuntos de personas que comparten una análoga ubicación en el mundo socio-histórico.

Así caracterizadas las comunidades con las cuales se realizaron las experiencias audiovisuales, es necesario encauzar una serie de aclaraciones a respecto de la construcción del modelo de captación de información. Dada la premisa de que los receptores de discursos operan una distorsión de éstos sobre la base de códigos propios, la decisión de "ver un video" con la gente para luego profundizar la recepción de la audiencia a través de una discusión grupal guiada por un moderador (investigador), pretende ser una respuesta más adecuada al dilema de cómo captar algo tan evanescente para la investigación social como son los procesos internos que regulan las capacidades interpretativas de los sujetos respecto del discurso televisivo. En contraposición con la modalidad clásica de grupo experimental y grupo de control, que supone el aislamiento de la variable independiente (emisión televisiva) para confrontarla con la variable dependiente (recepción), "ver un video con la gente" se propone aquí como un diseño de sentido heurístico más blando y que permite una mayor sensibilidad del 
dispositivo para la captación de los procesos de interpretación dados en el seno de una comunidad de apropiación. En efecto, la recepción no puede ser artificialmente aislada de un conjunto de factores (como las tradiciones de las comunidades de apropiación, los prejuicios de los sujetos y sus filiaciones políticas) que operan en ella de forma central. Por cierto, el giro hermenéutico de las ciencias sociales de las últimas décadas, ha puesto de relieve la importancia que tales factores - prejuicios, filiaciones, tradiciones - desempeñan en los procesos de comprensión (GADAMER, 1993).

Este diseño pretende, por lo tanto, aproximarse a la complejidad del problema de la recepción, sin dejar de lado aspectos cruciales de la cuestión de la interpretación en la vida cotidiana que hubieran probablemente pasado desapercibidos en un modelo de experimentación más "duro". Sin embargo, no se desechó la intención de establecer relaciones causales entre la variable independiente (discurso televisivo) - controlada durante la experimentación - y la dependiente (en nuestro caso, la recepción), sino que se apuntó a complementar los modelos clásicos de investigación experimental (CAMPBELL; STANLEY, 1973) con la discusión que aborda la problemática de la etnografía de la recepción (HALL, 1993), sobre la base de que la comunicación no es directa ni unidireccional. Así, se propuso utilizar un modelo experimental que pudiera estimar la causación "distorsionada" entre la esfera de la enunciación (los contenidos temáticos y discursivos del estímulo audiovisual) y la esfera del reconocimiento (los contenidos que aparecen en la recepción de aquellos discursos).

El estímulo audiovisual aplicado consistió en la realización de un montaje de fragmentos televisivos que evocaran "la idea de nación". Su función fue proveer un corpus de fragmentos de materiales televisivos que sugirieran a los participantes ciertas series temáticas sobre la idea de nación. El audiovisual fue utilizado como estímulo disparador. No obstante, el trabajo de interpretación de los grupos focales no se circunscribió a los contenidos del video, sino, en una esfera más amplia, a las cuestiones que éste evocaba. El montaje del corpus audiovisual fue realizado de forma artesanal por los investigadores, y se constituyó en base a la captación de material televisivo considerado pertinente para los objetivos del estudio en distintas franjas horarias. Se trata por 
lo tanto de pequeños fragmentos de discurso televisivo extraído de programas culturales, publicidades y notas periodísticas, cuyo montaje fue realizado con la intención de que los fragmentos se sucedieran de forma desordenada y veloz, a manera de simular las formas como la televisión suele presentar sus contenidos.

Como herramienta intermedia entre la esfera de la emisión (estímulo audiovisual) y la de la recepción (grupos focales), se contó con un guión extraído analíticamente por los investigadores del corpus televisivo. La función del guión fue doble: se utilizó como insumo para la confección de la guía de pautas, y sirvió como elemento de confrontación con la esfera del reconocimiento surgida del material producido en las experiencias audiovisuales.

Para el acceso a las comunidades de apropiación se realizaron contactos personales con los trabajadores de YPF. Inicialmente, se pactaron entrevistas individuales con trabajadores de larga trayectoria en la empresa, quienes permitieron conocer el ámbito de trabajo y contar con información previa a las experiencias audiovisuales. No se registraron mayores dificultades en el consentimiento de los grupos a la participación.

\section{SOBERANÍA PETROLERA}

Los trabajadores del petróleo reproducen en los discursos recuperados en nuestro trabajo de campo, los términos de una periodización de la historia de YPF, transcurrida en las últimas décadas: al largo periodo de control estatal, iniciado en 1922 con su fundación, le sucede la privatización como un momento trágico y de pérdida de recursos. La privatización se marca en 1992, pero parece profundizarse según los discursos que analizamos con la compra de la empresa por parte de Repsol, de capitales españoles. En lo que sigue, nos confrontaremos con algunos de los testimonios recogidos.

....yo trabajé con un argentino y un gallego ${ }^{4}$ y el gallego era como el virrey del barco, por más que había un capitán argentino, porque lo exige el gremio argentino, el gallego este

4 Por "gallego" se entiende, en el lenguaje popular de Argentina, a todo aquel nacido en España. 
que no figuraba ni siquiera en el staff, y eso era una cosa así, por ser gallego era intocable, a menos que otro gallego vea que anda para atrás, lo movían o lo mandaban a España (Entrevista YPFiano 1).

yo sentía que Repsol no era amigo, si bien estaba dando trabajo pero yo estaba haciendo algo para que él me pague, no era gratis lo que me estaba dando, yo estaba dando parte de mi vida, yo seguía haciendo mi trabajo con responsabilidad, cuidando mi tierra, pero yo sabía que lo que estaban sacando era mi sangre (...) Y no sé si era claro, pero me daba cuenta que se repetía la historia, eran los espejitos de colores a cambio de nada (Entrevista YPFiano 2).

Se repite en las entrevistas la referencia al período de control mayoritario por parte de Repsol como un momento de fuga de capitales y de descuido por los recursos naturales nacionales, aunque es en estas citas que incluimos donde aparecen fuertes referencias a la colonización, con reconocidas metáforas que se han instalado en el lenguaje cotidiano. Este momento histórico es observado por los trabajadores de mayor trayectoria como uno de derrumbe de determinados valores o significados. Incluso encontramos referencias a una "entrega" del petróleo, equiparada a la entrega de la bandera como símbolo nacional.

P: Y en función de lo que decís vos ¿Se compara con la YPF de antes? La YPF original, estatal.

R: Y no, (....) lo que yo recuerdo de mi viejo es que le pagaban los pasajes, los hoteles, en el caso de los que viajaban en su auto les pagaban el combustible, esas cosas, y recuerdo que la gente de YPF (...) era parte de YPF, vos los ves con un orgullo de pertenecer a YPF

P: ¿Y eso hoy?

R: No, hoy día nada de eso, por ahí entre los más viejos, ... pero después en el resto, no está esta pertenencia (Entrevista YPFiano 1). 
Un periodo anterior, que simboliza no solamente un Estado protector de los trabajadores del petróleo, en el que las políticas de bienestar eran una característica central, sino también en el que los trabajadores construían una fuerte pertenencia a su empleo y su actividad. Por oposición, cuando se indaga en la situación posterior, del período de la privatización, los testimonios reunidos dan cuenta de posicionamientos contrarios respecto al presente de los trabajadores petroleros:

P: El trabajo que ustedes hacen, ¿creen que contribuye a la Nación?

R: iBastante! Cuando nosotros con el impuesto a las ganancias, nomás, que nos sacan de a 5 mil pesos por mes, qué no vamos a aportar!

R: El impuesto a las ganancias, los descuentos de ley...

P: Claro, digamos, vos no te das cuenta el beneficio de la Nación cuando para la producción.

R: Te das cuenta cuando le cerramos las válvulas (Grupo focal 1).

El trabajo en YPF y en el sector petrolero en general, es observado como una actividad económica más, cuya contribución a la nación es puramente monetaria y se resume en el pago de impuestos. Incluso es comparable con profesiones como la docencia o la medicina, que aparecen mencionadas en entrevistas al compararse rangos salariales. El aporte que esa actividad implica para la Argentina ni siquiera depende de su trabajo, según mencionaron estos trabajadores, sino que se vincula con el valor del barril en el ámbito internacional.

Entre los trabajadores petroleros con trayectorias más recientes en YPF, incluso es más evidente el pesimismo al explorar la percepción sobre el trabajo que realizan. Lo que recibe un especial reconocimiento es la permanencia de la trayectoria en la actividad - incluso intergeneracional -, pero no se encuentra una autopercepción especial ni la idea de ser considerados como centrales para el desarrollo nacional por el resto de la comunidad. 
Nosotros la tenemos bien marcada y nuestra vida se marca ¿por qué? Mi padre fue petrolero, nosotros somos petroleros, muchos de nuestros hijos son petroleros y van a seguir siéndolo probablemente un tiempo más (Entrevista YPFiano 4).

Finalmente, se reconoce un cambio desde 2012, con el proceso de renacionalización de los recursos petrolíferos, esto es, con la recuperación de la mayoría accionaria por parte del Estado argentino, en ese momento gobernado por Cristina Fernández de Kirchner. Aun cuando en el momento en que se anunció la medida tomada por el gobierno circularon discursos que sostenían la expectativa de un retorno a condiciones de soberanía energética y control estatal de la producción petrolera, entre los trabajadores que entrevistamos esta medida parece haber sido tomada - desde el punto de vista de la modalidad de sus trabajos - con la trascendencia que podía esperarse. Así surge de los siguientes testimonios:

Nosotros que trabajemos para una operadora estatal o trabajemos para una operadora internacional, (...) es lo mismo (Grupo Focal 1).

(...) es lo mismo, trabajes para el Estado argentino o para otra empresa internacional, es exactamente lo mismo (Grupo de petroleros privados).

Estos discursos "no idílicos" respecto a la condición estatal en relación a la privada de las empresas petroleras se emparenta con la ausencia de un ideograma presente en el período más heroico de YPF, entre las décadas del '50 y del '70, por el cual se asumía que trabajar en la producción de petróleo se asociaba con la producción de soberanía nacional. No hemos encontrado estas ideas entre los registros de nuestras experiencias, en las que - como en tantas otras actividades de esta época - se comprueba un predominio de las cuestiones económicas.

P: Pero en definitiva, el trabajo que ustedes realizan ¿es importante para la cuestión argentina?

R: Sí, económicamente. 
R: Económicamente, es un negocio, pero es internacional aparte de ser para la Argentina (Grupo focal 1)

Resulta elocuente, el significado atribuido al trabajo por parte del grupo de trabajadores reunidos en el Sindicato de Petroleros Privados de Santa Cruz:

Yo te digo para mí es llevar el pan a la casa ¿entendés? Porque es una explotación de los recursos naturales... pero donde toda la plata o el grueso se lo llevan afuera y lo que queda acá son migajas. Migajas, y dejan a las poblaciones o los pueblos o los pocos pueblos que hay... sin nada, porque tampoco dejan nada más allá de lo que uno lleva a su casa, que es el pan o el sueldo que saca a fin de mes... (Grupo de Petroleros privados).

La enajenación que implica una relación no consumada con el producto de la extracción del petróleo por parte de estos trabajadores, se observa en estas experiencias en la abstracción con la que se percibe la relación asimétrica entre la nación y las circunstancias del mercado internacional.

Sin ir más lejos, lo que está pasando hoy por la baja del barril y todo eso no es solamente por la Argentina, sino a nivel internacional. Claro, los valores del barril entonces ahí le sirve a la empresa, les sirve a los operadores, le sirve a la nación, y también le sirve a la gente... Pero hoy en día como está en baja, o sea ahí ya el gobierno empieza a medir costos, en donde empieza a ver que no le cierran los números, entonces ahí es en donde empiezan a fijarse que la gente que es la que explota todo eso, está de más, no le cierran los números entonces ahí empiezan a haber despidos... (Grupo focal 1).

\section{REFLEXIONES FINALES}

Pensadores latinoamericanos de la primera mitad del siglo XX, como Manuel Ugarte (2010), afirmaron que los proyectos de explotación del petróleo de las naciones de América Latina eran nacionalistas porque apuntaban a lograr una unidad nacional, a la vez 
que impedían el paso de capitales e intereses extranjeros en una nueva afirmación de independencia y soberanía. Podemos agregar que esa identificación de la nación con los recursos naturales y las políticas de explotación supone imaginar (en el sentido de crear la imagen de) cierta homogeneidad espacial y temporal tal como suponía Anderson sobre la construcción del nacionalismo. La difusión masiva de las imágenes de los elementos que componen lo nacional permite cierta simultaneidad de la experiencia y la construcción de un marco general que sobrepasa las particularidades (VERSTRAETE, 2002).

Las naciones latinoamericanas, siguiendo esa línea andersoniana, se construyen con un fuerte tono autorreferencial, ya que necesitan de esa mirada propia para su identidad y desarrollo. El proteccionismo de las riquezas que se consideran propias define a una nación y delinea la comunidad nacional que velará por sus intereses. Esa idea de nación funciona como la abstracción que casi anónimamente regula esos recursos. Parafraseando a Ginette Verstraete (2002), el petróleo no sólo se consolidó como una tecnología de la producción industrial sino más bien como una tecnología de la representación. Esas referencias a lo material persisten en un lugar destacado de las ideas de nación, aun cuando la ecuación social haya variado y el proteccionismo ya no aparezca como uno de los pilares de la ideología estatal.

En la región patagónica de Argentina, en dónde se extrae "el oro negro", hay una circulación especial de las riquezas naturales. Se extraen de la tierra pero se pierden en su gran mayoría tras los mares, más allá de los límites de la nación. Hay flujos de dinero - a veces - atados a designios sobre los que los trabajadores del petróleo en su mayoría no disponen de posibilidad alguna de intervenir, y en los que con frecuencia, siquiera resulta posible una representación cabal, como es el caso del aumento del precio internacional del barril.

En las representaciones de la idea de nación de parte de los trabajadores del petróleo que participaron de nuestras experiencias, se detecta una zona nítida de rechazo al control extranjero de los recursos naturales nacionales. La oposición de plano a la experiencia de la privatización de la empresa nacional de petróleo 
apareció en todos los casos, con invocaciones claras de defensa de las tradiciones culturales de la nación autónoma. No obstante, y en aparente contradicción con lo anterior, se aprecia también una percepción no idílica de la renacionalización, y la preminencia en algunos casos - como en el grupo que tuvo lugar en el sindicato de petroleros privados - de un muy bajo grado de identifiación cultural, que tiende a reemplazarse por una ética utilitaria de la producción del capital. Aún así, el rechazo al despojo de los recursos naturales de la nación se presenta entre los trabajadores del petróleo como uno de los elementos fundantes de la comunidad nacional.

\section{REFERENCIAS}

ANDERSON, B. Comunidades imaginadas: reflexiones sobre el origen y la difusión del nacionalismo. México: FCE, 1993.

ANDERSON, B.(Ed.). Introduction. En: BALAKRISHNAN, Gopal (Ed). Mapping the Nation. Londres: Verso, 1996.

ANG, I. Watching Dallas: soap opera and the melodramatic imagination. London: Routledge, 1985.

BALAKRISHNAN, G. The national imagination. En: BALAKRISHNAN, Gopal (Ed.) Mapping the Nation. Londres: Verso, 1996.

CALHOUN, C. La importancia de Comunidades imaginadas de Benedict Anderson. Debats, v. 130/1, p. 11-17, 2016. Disponible en: <https:// es.scribd.com/document/370066086/La-importancia-de-ComunidadesImaginadas-y-de-Benedict-Anderson >. Fecha de acceso:16 oct.2018.

CAMPBELL, D.; STANLEY, J. Modelos experimentales y cuasiexperimentales de investigación social. Buenos Aires: Amorrortu, 1973.

CHATTERJEE, P. La nación en tiempo heterogéneo y otros estudios subalternos. Buenos Aires: CLACSO; Siglo XXI, 2008.

CLIFFORD, J.; MARCUS, G. (Eds.). Writing Culture: the poetics and politics of etnography. [S.l.]: University of California Press, 1986.

ECHEVERRÍA, B. Modernidad y blanquitud. México: Era, 2010.

GADAMER, H. G. Verdad y método I. Salamanca: Sígueme, 1993. 
HALL, S. Culture, community, nation, Cultural Studies, v. 7, n. 3, p. 349363, 1993. DOI: $10.1080 / 09502389300490251 .$.

JENSEN, K. B. Qualitative audience research: Toward an integrative approach to reception, Critical Studies in Mass Communication, v.4, n.1, p. 21-36, 1987. DOI: 10.1080/15295038709360110.

MARCUS, G.E..; FISCHER, M. M.J. Antropology as Cultural Critique: an experimental moment in the Human Sciences. Chicago: University of Chicago Press, 1986.

MORLEY, D. The nationwide audience: structure and decoding. Londres: BFI,1980.

PETRACCI, M. La agenda de la opinión pública a través de la discusión grupal: una técnica de investigación cualitativa: el grupo focal. En: KORNBLIT, A.L. (Coord.) Metodologías cualitativas en Ciencias Sociales: modelos y procedimientos de análisis. Buenos Aires: Biblos, 2004. p. 77-89.

RENÁN, E. ¿Qué es una nación? En: FERNANDEZ BRAVO, A. (Comp.). La invención de la nación: lecturas de la identidad de Herder a Homi Bhabha. Buenos Aires: Manantial, 2001. p. 53-66.

ROSALDO, R. Reimaginando las comunidades nacionales. En: VALENZUELA ARCE, J. M. (Coord.) Decadencia y auge de las identidades: cultura nacional, identidad cultural y modernización. Tijuana: El Colegio de la Frontera Norte, 1992. p. 191-201.

UGARTE, M. La patria grande. Buenos Aires: Capital Intelectual, 2010.

VERNIK, E. Comunidades cercadas. La exclusión urbana en la televisión y en la vida, Perfiles Latinoamericanos. Revista de FLACSO, México, n. 9, 1996. p. 85-100.

VERSTRAETE, G. Railroading America. Theory, Culture \& Society, v. 19, n. 5-6, 2002. p. 145-159. 


\section{APÉNDICE METODOLÓGICO}

El guión audiovisual editado a partir de fragmentos de discursos de noticias tenía una extensión aproximada de 7 minutos y condensaba múltiples imágenes que aluden a dimensiones de la nación, tales como las que sirven de título de sus tres bloques. El guión audiovisual no nos ofrece una visión completa sino más bien una multiplicidad de puntos de vista que son coherentes en algunos de los aspectos e incompatibles en otros.

En lo que sigue, se presenta una descripción del mismo; y a continuación, los significados otorgados por los investigadores, los cuales servirán para contrastarse con las interpretaciones surgidas del discurso de los entrevistados.

\section{BLOQUE 1 - HIMNO NACIONAL - PATRIA}

- Suena la introducción del himno nacional argentino, versión clásica, al tiempo que se ve una bandera nacional argentina.

- Suena el himno nacional argentino cantado por Pablo Lescano, se ve gente en una tribuna cantando el himno, y el logo del programa televisivo "Pasión"

- Aparece Pablo Lescano cantando, con ropa de la selección nacional de futbol, con el zócalo: "Exclusivo: Damas Gratis interpreta el himno nacional".

- Pablo Lescano, nuevamente en primer plano, dice "canten giles" en medio de las estrofas del himno.

- Cambia la secuencia, y suena el himno nacional interpretado por la orquesta de los Granaderos a Caballo, pero en una versión ligeramente diferente a la clásica, mientras se ve en un escenario a la ex-presidente, Cristina Fernández, con la mano en el corazón, cantando el himno nacional junto a figuras del espectáculo.

- Se muestra un paneo general de la gente asistente al acto, y se pueden ver las pantallas gigantes, con el Cabildo de Fondo.

- Se ve la orquesta de los Granaderos a caballo tocando y una pareja de bailarines en el escenario, y nuevamente el público con las banderas. 


\section{SIGNIFICADOS ATRIBUIDOS:}

Se presentan dos formas de interpretar el himno nacional argentino bien controversiales. La idea principal es mostrar a los diferentes grupos seleccionados para realizar la experiencia audiovisual, ideas disímiles. Así es que en un primer término del guion, los espectadores habrán de observar a Pablo Lescano, líder del grupo de cumbia villera "Damas gratis", cantando informalmente el Himno Nacional Argentino. En el extremo opuesto, se presenta a la ex presidenta Cristina Fernández de Kirchner entonando las estrofas del himno nacional argentino. Es ceñidamente la embestidura de "Presidente" la que genera que se trate de una interpretación más formal. Aunque sin la formalidad que requiere un acto de gobierno respecto a la canción patria que identifica a los argentinos juntamente con la bandera, la escarapela y el escudo nacional. Si bien ambas versiones se las puede considerar transgresoras respecto de la versión tradicional, de una manera u otra, el núcleo del recorte tiende a que los grupos analicen el himno en función de su relación con la nación y la globalización. No pretendemos acuerdos o desacuerdos con ambas interpretaciones. Lo que más nos interesa es que los grupos se pregunten, sobre el himno, la nación en nuestro tiempo.

\section{BLOQUE 2: YPF - REPSOL}

- $\quad$ Se ve una foto de un pozo petrolero con el título "YPF, camino a la soberanía energética" y el logo del canal del estado, "TVP (vivo)".

- Sigue un video en blanco y negro de un pozo petrolero funcionando, el logo clásico de YPF en un tanque de almacenamiento, el cielo, nuevamente un pozo un tanque de almacenamiento y un Relator en Off dice "YPF ha sido en la historia la columna vertebral de la Patagonia y de la República en materia energética, una empresa de bandera nacional", todo con el logo de TVP (vivo).

- Se ve al ex presidente Carlos Menem, en una entrevista de un notero, con el zócalo del noticiero del canal del Estado "Carlos Menem, presidente de la nación ORIGEN, 
DESARROLLO Y PRIVATIZACIÓN. Archivo 18/03/1993", diciendo "la privatización más grande de todos los tiempos en el mundo y el éxito ha sido rotundo".

- Mientras se ven imágenes de pozos petroleros, refinerías, petróleo burbujeante, un relator en off dice "A contramano de los países que pusieron a resguardo (aparece un caño con la leyenda "Venezuela") de intereses externo y las pujas del mercado sus recursos estratégicos, en los 90 la Argentina se desprendió de su principal activo, el petróleo".

- Imágenes de una manifestación, donde se pueden ver a varios policías, y a una persona con una máscara, con el anuncio del canal del Estado que dice: "archivo 1997, Tartagal, Salta".

- Con el mismo anuncio del canal, se ve a un señor, entrevistado por un notero, que dice "soy petrolero, 20 años trabajando en el petróleo, se vendió, se regaló todo esto y no, no dejaron una fuente alternativa de trabajo, la gente no tiene, no tiene en que trabajar".

- En una alocución en la Casa Rosada, del 15/04/2012, la ex presidente Cristina Fernández, en frente a una bandera nacional, y con la ciudad de Buenos Aires de fondo, y el anuncio del canal del Estado que versa "Cristina Fernández de Kirchner, presidenta de la nación CRÓNICA DE LA EXPROPIACIÓN", dice "De proseguir esta política de vaciamiento, de no producción, de no exploración, prácticamente nos tornaríamos con el nivel de crecimiento, actividad de industrias, trabajadores, en un país inviable, pero lo más grave... nos tornaríamos en un país inviable por políticas empresariales y no por falta de recursos".

- Se ven imágenes de una zona semi desértica, con un pozo petrolero en funcionamiento y el zócalo del canal anuncia "Loma Campana - Vaca Muerta, Neuquén. Cómo se trabaja en la reserva más importante de Latinoamérica". Quien parece va arriba del avión que toma las imágenes dice "De esta forma se puede divisar la meseta patagónica en todo su esplendor y las torres perforadoras trabajando a pleno". 
- Se ven corridas en una manifestación, en lo que parece una plaza, con banderas verdes y banderas rojas, de las cuales no se puede leer la inscripción, se ven personas aplaudiendo y una voz de mujer que grita "fuera, fuera, fuera Chevron fuera, fuera, fuera, fuera Chevron fuera, fuera, fuera, fuera Chevron fuera".

- La ex presidente Cristina Fernández en la inauguración de Tecnópolis dice "Pero como siempre digo, la dignidad regional no se sostiene únicamente con discursos, sino que la dignidad nacional se sostiene haciendo cosas como estas. Incorporando mayor tecnología, mayor valor agregado $y$ dándole oportunidades de educación, de preparación a todos los chicos argentinos, para que todos, desde Loma Blanca, allá arriba a 4200 metros, hasta Ushuaia tengan la misma oportunidad que el resto de los argentinos, de aprender, de educarse, de elegir".

- La ex presidente Cristina Fernández, en el mismo acto de inauguración, de la mano de un niño vestido con ropas típicamente collas (atrás de puede ver al exgobernador Scioli) dice "Bueno acá Eyen les quiere recitar, en realidad me la quería recitar a mí, pero yo quiero que se las recite a ustedes. Agarrá el micrófono y dale".

- El niño recita: No te rías de un colla de Fortunato Ramos.

\section{SIGNIFICADOS ATRIBUIDOS:}

La segunda parte del guion se vincula con una suposición relativa a la visión de cómo la empresa petrolera YPF fue mutando: primero desde su fundación creada por el Estado argentino en 1922 durante la presidencia de Hipólito Yrigoyen - bajo el impulso intelectual de Enrique Mosconi -, dedicada a la exploración, explotación, distribución y venta de petróleo y sus derivados. A finales de la década del '80, empleaba directa e indirectamente cerca de 50.000 trabajadores. En un segundo momento, durante el gobierno presidido por Carlos Menem, en el marco del neoliberalismo económico, se gestó la privatización de la petrolera YPF. En 1992, se realizaron las primeras reformas que convirtió a la petrolera 
estatal en YPF S.A, para luego convertirla en Repsol YPF, cuando la empresa española Repsol adquirió la mayoría accionaria. En dicho proceso, se produjo el desempleo de la mayoría de los trabajadores, pues el personal se redujo un $85 \%$ aproximadamente. Un tercer momento de este devenir de la empresa ocurrió en el año 2012, cuando la presidencia encabezada por Cristina Fernández de Kirchner, mediante el proyecto de ley denominado “De la soberanía hidrocarburífera de la República Argentina", produjo la re nacionalización de la empresa petrolera.

\section{BLOQUE 3- RECURSOS NATURALES}

- Imagen de una señora con atuendo típico de pueblo originario, con otras personas mientras suenan instrumentos de viento y percusión. Seguidamente aparece un cartel que dice "VOZ" traslúcido y en primer plano "son fuerzas que tiene su voz.

- Mientras se ve un pozo petrolero funcionado una voz de mujer en off dice: "hoy tenemos aquí de vecinito los petroleros, la empresa petrolera".

- Mientras un hombre, una mujer y un niño, camina de la mano por un campo de matas y claramente sopla el viento, la señora en off dice: "Llegaron sin pedir permiso, sin presentarse...

- Se ven un recorte de un titular de diario "Valdría 8.000 millones. Aprobaron la venta de YPF. El oficialismo con gran esfuerzo y algunas promesas al sindicalismo, logró votar la privatización de la mayor empresa del país. La ley autoriza a vender el 70\% de las acciones, otro que no llega a leerse y un grafiti que dice "Sobich - Repssol avanza para la muerte".

- Se ve una especie de asamblea y una señora dice "La comunidad se organiza, nos organizamos como pueblo, para defender ese espacio territorial".

- Un señor al lado de una salamandra a leña dice "No somos de otro lado, somos nacidos y criados de acá". Mientras habla se ven unos niños jugando con una vivienda precaria detrás. 
- $\quad$ Aparece un cartel de fondo que versa "Estas voces son las que los mapuches escuchan".

- Mientras se ven imágenes en sepia de campos intervenidos por la actividad petrolera una voz de mujer dice "Vino todo de repente, la gente se asusta de lo que estaba viendo, es decir se asustó de tanta destrucción, en el espacio.

- $\quad$ Aparece la mujer que habla, en el mismo patio donde estaban los niños jugando y continua "Vos vas a las comunidades que tienen el petróleo abajo y no hay luz, no hay gas, no hay agua, ni nada.

- Aparece una mujer de cabellos blancos a la intemperie y dice:

- Cansado de tomar agua de la laguna, cansada muchas veces, de andar en el campo, muchas veces tenemos que tomar de un charco de agua, y esa agua está contaminada, y de esa manera nos están matando. Tal vez ahora no nos pueden matar... no nos pueden como antes, que nos mataban con armamento, pero sí, nos siguen matando de esa manera.

\section{SIGNIFICADOS ATRIBUIDOS:}

Finalmente en el tercer fragmento del guion audiovisual, mostramos realidades contrapuestas con el fin de reflexionar sobre la pregunta ¿Quiénes son los dueños de la tierra? ¿Cuáles son los derechos de los pobladores de las regiones donde se realiza la extracción petrolera? Y el problema, no menor en los lugares donde se concibe la explotación petrolera propiamente dicha, de la contaminación del agua potable producto de la extracción. 